\title{
SISTEM PAKAR DIAGNOSIS KELAINAN SISTEM PENCERNAAN PADA ANAK DENGAN METODE DAMPSTER SHAFER
}

\author{
Yuki Saputra $^{1)}$, Sumijan $^{2)}$, Abulwafa Muhammad ${ }^{3)}$ \\ 1) Yuki Saputra, Indonesia \\ 2) Dr. Ir. Sumijan, M.Sc, Indonesia \\ 3) Abulwafa Muhammad, S.Kom, M.Kom, Indonesia \\ e-mail: yukisaputra10@gmail.com ${ }^{1)}$, soe@upiyptk.org ${ }^{2}$, abulwafa@upiyptk.ac.id $^{3)}$
}

\begin{abstract}
ABSTRAK
Adapun permasalahan yang sering terjadi pada anak adalah sebagai berikut: Gumoh, disfagia, Cyclic vomiting syndrome, Kolik, Diare, Sembelit. Dempster-Shafer adalah suatu teori matematika untuk pembuktian berdasarkan belief functions and plausible reasoning (fungsi kepercayaan dan pemikiran yang masuk akal), yang digunakan untuk mengkombinasikan potongan informasi yang terpisah (bukti) untuk mengkalkulasi kemungkinan dari suatu peristiwa. Teori ini dikembangkan oleh Arthur P. Dempster dan Glenn Shafer. Secara umum teori Dampster-Shafer ditulis dalam suatu interval Belief, Plausibility (Triara Puspitasari et al,2016). Mampu menghasil jenis penyakit yang dialami pasien dan memberikan rekomendasi pengobatan apa yang harus dilakukan oleh pasien.
\end{abstract}

Kata Kunci : Sistem Pakar, Dampster Shafer, Kelainan Pencernaan pada anak,

\begin{abstract}
The problems that often occur in children are as follows: Spit up, dysphagia, Cyclic vomiting syndrome, Colic, Diarrhea, Constipation. Dempster-Shafer is a mathematical theory for proof based on belief functions and plausible reasoning, which are used to combine separate pieces of information (evidence) to calculate the probability of an event. This theory was developed by Arthur P. Dempster and Glenn Shafer. In general the Dampster-Shafer theory is written in a Belief, Plausibility interval (Triara Puspitasari et al, 2016). Able to produce the type of disease experienced by the patient and provide recommendations for what treatment should be done by the patient.
\end{abstract}

Keywords: Expert System, Dampster Shafer, Digestive disorders in children

\section{PENDAhUluan}

1.1 Latar Belakang Masalah

Perkembangan komputer saat ini telah mengalami banyak perubahan yang sangat pesat, seiring dengan kebutuhan manusia yang semakin banyak dan kompleks. Komputer yang pada awalnya hanya digunakan oleh para akademis dan militer, kini telah digunakan secara luas dalam berbagai bidang, misalnya: Bisnis, Kesehatan, Pendidikan, Permainan dan sebagainya. Hal ini mendorong para ahli untuk semakin mengembangkan komputer agar dapat membantu kerja manusia atau bahkan melebihi kemampuan kerja manusia. Kecerdasan buatan atau artificial intelligence merupakan bagian dari ilmu komputer yang membuat agar mesin (komputer) dapat melakukan pekerjaan seperti dan sebaik yang dilakukan oleh manusia. Sistem cerdas (intelligent system) adalah sistem yang dibangun dengan menggunakan teknik-teknik artificial intelligence. Beberapa yang dipelajari dalam kecerdasan buatan dan salah satunya adalah teori Dampster Shafer.

Sistem pakar (Expert System) adalah salah satu cabang dari AI (Artificial Intelligence) khusus untuk penyelesaian masalah tingkat manusia yang pakar. Sistem pakar adalah sistem yang menggunakan pengetahuan manusia yang terekam dalam komputer untuk memecahkan persoalan yang biasanya memerlukan keahlian manusia (Arthur Daniel Limantara1 et al, 2017).

Metode Dempster Shafer pertama kali diperkenalkan oleh Dempster, yang melakukan percobaan model ketidakpastian dengan range probabilities dari pada sebagai probabilitas tunggal. Kemudian pada tahun 1976 Shafer mempublikasikan teori Dempster itu pada sebuah buku yang berjudul Mathematical Theory Of Evident. DempsterShafer Theory Of Evidence, menunjukkan suatu cara untuk memberikan bobot kenyakinan sesuai fakta yang dikumpulkan. Pada teori ini dapat membedakan ketidakpastian dan ketidaktahuan. Teori Dempster-Shafer adalah representasi, kombinasi dan propogasi ketidakpastian, dimana teori ini memiliki beberapa karakteristik yang secara instutitif sesuai dengan cara berfikir seorang pakar, namun dasar matematika yang kuat (Mikha Dayan Sinaga, Nita Sari Br. Sembiring, 2016).

Penggunaan Sistem Pakar dengan metode Dampster Shafer banyak digunakan untuk menyelesaikan permasalahan dalam berbagai bidang penyakit seperti Sistem Pakar Diagnosa Penyakit Gigi Dan Mulut 
Menggunakan Metode Dempster Shafer (Kharismadhan Zakaria, 2015), Sistem Pendukung Keputusan Deteksi Dini Penyakit Stroke Menggunakan Metode Dempster-Shafer (Deby Putri Indraswari et al, 2015), Implementasi Metode Dempster Shafer Dalam Sistem Pakar Diagnosa Anak Tunagrahita Berbasis Web (Triara Puspitasari et al, 2016), Implementasi Metode Dempster-Shafer untuk Mendeteksi Penyakit Diabetes Mellitus (Januar Dwie Amanda et al, 2018), Deteksi Sepsis pada Bayi Menggunakan Metode Dempster Shafer (Wayan Ryon Waryanta et al, 2016), Aplikasi Sistem Pakar Untuk Mendiagnosa Penyakit Gangguan Saraf Dengan Metode Dempster Shafer Berbasis Android (Budiman et al, 2016).

Berdasarkan latar belakang masalah diatas maka penulis mengajukan judul penelitian dengan judul "SISTEM PAKAR DIAGNOSIS KELAINAN SISTEM PENCERNAAN PADA ANAK DENGAN METODE DAMPSTER SHAFER".

\subsection{Perumusan Masalah}

Perumusan masalah pada penelitian ini antara lain, yaitu:

1. Bagaimana menerapkan Sistem Pakar menggunakan metode Dampster Shafer untuk menentukan kelainan sistem pencernaan pada anak?

2. Bagaimana merancang Sistem Pakar untuk menentukan kelainan sistem pencernaan pada anak berdasarkan gejala-gejala yang ada?

3. Bagaimana merancang Sistem Pakar untuk memberikan solusi atau pencegahan pada kelainan sistem pencernaan pada anak?

\subsection{Batasan Masalah}

Agar terarahnya pembuatan penelitian ini, maka dibuatlah batasan masalah terhadap masalah yang diteliti. Adapun batasan masalah dalam penelitian ini yaitu :

1. Dengan penggunaan aplikasi Sistem Pakar ini hanya menampilkan gejala-gejala yang ditimbulkan oleh kelainan sistem pencernaan pada anak serta solusinya.

2. Dengan menggunakan metode Dampster Shafer akan menghasilkan hasil berupa kepastian yang akan sesuai dengan data yang diisi oleh pengguna. Penggunaan aplikasi ini hanya menampilkan informasi kelainan sistem pencernaan pada anak serta solusi atau pencegahan berbasis web.

1.4 Tujuan Penelitian

Tujuan yang akan dicapai dalam penelitian ini adalah sebagai berikut :

1. Merancang Sistem Pakar dengan metode Dampster Shafer untuk menentukan kelainan sistem pencernaan pada anak.

2. Merancang sistem pakar untuk memberikan solusi kelainan sistem pencernaan pada anak.

3. Membangun dan mengimplementasikan aplikasi Sistem Pakar untuk menentukan kelainan dan solusi/pencegahan pada sistem pencernaan pada anak dengan menerapkan metode Dampster Shafer berbasis web.

4. Menguji hasil dari Sistem Pakar dalam menentukan kelainan dan solusi/pencegahan pada sistem pencernaan pada anak.

1.5 Manfaat Penelitian

Manfaat dalam penelitian ini adalah sebagai berikut :

1. Memberikan pengetahuan tentang kelainan sistem pencernaan pada anak dan gejala-gejalanya disertai tindakan yang harus diambil untuk pencegahannya sebagai langkah awal dalam mengantisipasi kelainan sistem pencernaan pada anak.

2. Diharapkan dapat memberikan manfaat pada bidang ilmu computer berupa tambhan referensi dalam penelitianpenelitian selanjutnya sehingga bermanfaat terhadap perkembangan Sistem Pakar dalam bidang kesehatan.

\section{TINJAUAN LiTERATUR [TIMES NEW ROMAN 13 POINTS]}

\subsection{Defenisi Kecerdasan Buatan}

Kecerdasan buatan berasal dari bahasa inggris "ArtificialIntelligence" atau disingkat AI, yaitu intelligence adalah kata sifat yang berarti cerdas, sedangkan artificial artinya buatan. Kecerdasan buatan yang dimaksud disini merujuk pada mesin yang mampu berpikir, menimbang tindakan yang akan diambil, dan mampu mengambil keputusan seperti yang dilakukan oleh manusia. Berikut beberapa defenisi kecerdasan buatan yang telah didefenisikan oleh beberapa ahli (Sutojo, T, et al: 2012).

Alan turing, ahli metematika berkebangsaan inggris yang dijuluki bapak komputer modern dan pembongkar sandi Nazi dalam era Perang Dunia II, menetapkan defenisi artifial intelligence : “ jika komputer tidak dapat dibedakan dengan manusia saat berbincang melalui terminal komputer, maka bisa dikatakan komputer itu cerdas,mempunyai kecerdasan". Menurut John McCarthy dan Stanford mendefenisikan kecerdasan sebagai " kemampuan untuk mencapai sukses dalam 
menyelesaikan suatu permasalahan”. Menurut Herbert Alexander Simon (june 15,1916-FebruarY 9,2001) : “Kecerdasan buatan (artificial intelligence) merupakan kawasan penelitian, aplikasi, dan instruksi yang terkait dengan pemrograman komputer untuk melakukan sesuatu hal yang dalam pandangan manusia atau cerdas". Kecerdasan buatan (AI) merupakan sebuah studi tentang bagaimana membuat komputer melakukan hal-hal yang pada saat ini dapat dilakukan lebih baik oleh manusia (Sutojo, T, et al: 2012).

\section{Defenisi Sistem Pakar}

Para ahli mendefinisikan AI secara berbeda-beda tergantung pada sudut pandang mereka masing-masing. Ada yang fokus pada logika berfikir manusia saja, tetapi ada juga yang mendefinisikan AI secara lebih luas pada tingkah laku manusia (Suyanto, $2014: 3$ ).

Sistem pakar merupakan cabang dari Artificial Intelligence (AI) yang cukup tua karena sistem ini mulai dikembangkan pada pertengahan 1960. Istilah sitem pakar berasal dari istilah knowledge-based expert system. Istilah ini muncul karena untuk memecahkan masalah, sistem pakar menggunakan pengetahuan seorang pakar yang dimasukkan ke dalam komputer. Seseorang yang bukan pakar menggunakan sistem pakar untuk meningkatkan kemampuan pemecahan masalah, sedangkan seorang pakar menggunakan sistem pakar untuk knowledge assistant (Sutojo, T, et al: 2012).

\subsection{Dampster Shafer}

Menurut penelitian yang dilakkan oleh Minardi, Joko 2016 : 85 Teori Dempster-Shafer adalah teori matematika bukti berdasarkan fungsi keyakinan dan penalaran yang masuk akal, yang digunakan untuk menggabungkan bagian yang terpisah dari informasi. DempsterShafer teori alternatif teori probabilistik tradisional untuk representasi matematis dari ketidakpastian. Metode Dempster-Shafer pertama kali diperkenalkan oleh Dempster, yang melakukan percoban model ketidakpastian dengan range probabilitas sebagai probabilitas tunggal. Kemudian pada tahun 1976 Shafer mempublikasikan teori Dempster tersebut pada sebuah buku yang berjudul Mathematical Theory of Evident. Secara umum teori DempsterShafer ditulis dalam suatu interval [Belief, Plausibility]. Belief (Bel) adalah ukuran kekuatan evidence dalam mendukung suatu himpunan proposisi. Jika bernilai 0 (nol) maka mengindikasikan bahwa tidak ada evidence, dan jika bernilai 1 menunjukkan adanya kepastian.

\section{Metodologi}

Dalam melakukan penelitian agar mendapat hasil seperti yang diharapkan, maka diperlukan kerangka kerja penelitian. Dimana kerangka penelitian yang dilakukan digambarkan seperti berikut:

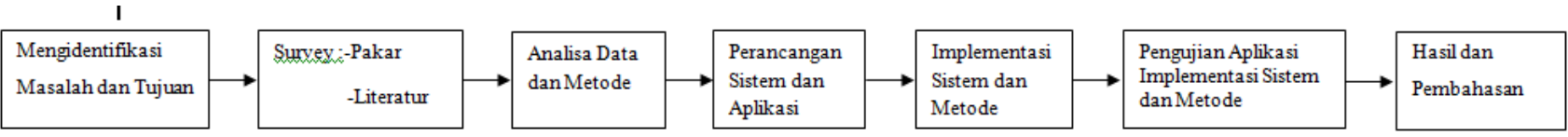

Gambar 3.1 Kerangka Penelitian

\section{HASIL DAN DISKUSI [TIMES NEW ROMAN 13 POINTS]}

Rule sebuah teknik respentasi pengetahuan sintax rule IF E Then H. Evidence (fakta yang ada) dan hipotesa atau kesimpulan yang dihasilkan.

Diket :

R1 = IF G01 AND G02 AND G03 AND G04AND G05 THEN P001

R2 = IF G04 AND G06 AND G07 AND G08AND G09THEN P002

R3 = IF G05 AND G10 AND G11 AND G12AND G13 THEN P003

R4 = IF G03 AND G04 AND G05 AND G13 AND G014 THEN P004

R5 = IF G05 AND G12 AND G14 AND G15 AND G016 THEN P005

R6 = IF G13 AND G16 AND G17 AND G18 AND G019 THEN P006

Tabel 4.4 Tabel Pertanyaan

\begin{tabular}{|c|l|c|}
\hline No & \multicolumn{1}{|c|}{ Gejala Penyakit Gangguan Perut Dan Pencernaan Pada Anak } & Pilihan \\
\hline 1 & Anak Memuntahkan Makanan Atau Cairan Susu Terlalu Sering & $\mathrm{x}$ \\
\hline 2 & $\begin{array}{l}\text { Warna Cairan Yang Dimuntahkan Anak Berwarna Kuning, Hijau Atau Disertai } \\
\text { Darah. }\end{array}$ & $\mathrm{x}$ \\
\hline 3 & Anak Susah Makan Atau Menolak Diberi Susu & $\sqrt{ }$ \\
\hline 4 & Anak Sulit Bernapas & $\sqrt{ }$ \\
\hline 5 & Menangis Berlebihan Atau Sangat Rewel Dan Tidak Nyaman. & $\mathrm{x}$ \\
\hline 6 & Tidak Bisa Mengonsumsi Makanan Kasar/ Bertekstur & $\mathrm{x}$ \\
\hline 7 & $\begin{array}{l}\text { Anak Muntah Terlihat Pada Tumpahannya Terdapat Bentukan Nasi Yang Masih } \\
\text { Utuh }\end{array}$ & \\
\hline
\end{tabular}




\begin{tabular}{|c|l|c|}
\hline 8 & Makan Lebih Lama & $\mathrm{x}$ \\
\hline 9 & Batuk Atau Muntah Selama Makan & $\mathrm{x}$ \\
\hline 10 & $\begin{array}{l}\text { Muntah Yang Muncul Pada Jam Yang Sama, Berlangsung Selama Durasi Waktu } \\
\text { Sang Sama, Serta Memiliki Intensitas Yang Sama Pula Dengan Muntah }\end{array}$ & $\mathrm{x}$ \\
\hline 11 & Muntah Yang Menyembur & $\mathrm{x}$ \\
\hline 12 & Demam & $\mathrm{x}$ \\
\hline 13 & Perut Tampak Membengkak & $\mathrm{V}$ \\
\hline 14 & Diare Yang Berkepanjangan & $\mathrm{x}$ \\
\hline 15 & Buang Air Besar Encer Dan Sering & $\mathrm{x}$ \\
\hline 16 & Darah Dalam Fases & $\mathrm{x}$ \\
\hline 17 & FrSekuensi Buang Air Besar (BAB) Kurang Dari 3 Kali Dalam Seminggu & $\mathrm{x}$ \\
\hline 18 & Setelah Buang Air Besar, Anak Merasa Tidak Nyaman Di Daerah Perutnya & $\mathrm{x}$ \\
\hline 19 & Feses Yang Keluar Nampak Seperti Feses Kambing, Berbentuk Kecil Dan Keras & \\
\hline
\end{tabular}

Proses pencarian dengan metode Dempster Shafer :

Jika diketahui gejala :

Tabel 4.5 Bobot Jawaban User

\begin{tabular}{|c|c|c|c|}
\hline No & Kode & Pilihan & Nilai \\
\hline 1 & G01 & $\mathrm{x}$ & 0 \\
\hline 2 & G02 & $\mathrm{x}$ & 0 \\
\hline 3 & G03 & $\sqrt{ }$ & 0,24 \\
\hline 4 & G04 & $\sqrt{ }$ & 0,15 \\
\hline 5 & G05 & $\sqrt{ }$ & 0,14 \\
\hline 6 & G06 & $\mathrm{x}$ & 0 \\
\hline 7 & G07 & $\mathrm{x}$ & 0 \\
\hline 8 & G08 & $\mathrm{x}$ & 0 \\
\hline 9 & G09 & $\mathrm{x}$ & 0 \\
\hline 10 & G10 & $\mathrm{x}$ & 0 \\
\hline 11 & G11 & $\mathrm{x}$ & 0 \\
\hline 12 & G12 & $\mathrm{x}$ & 0 \\
\hline 13 & G13 & $\sqrt{ }$ & 0,23 \\
\hline 14 & G14 & $\mathrm{x}$ & 0 \\
\hline 15 & G15 & $\mathrm{x}$ & 0 \\
\hline 16 & G16 & $\mathrm{x}$ & 0 \\
\hline 17 & G17 & $\mathrm{x}$ & 0 \\
\hline 18 & G18 & $\mathrm{x}$ & 0 \\
\hline 19 & G19 & $\mathrm{x}$ & 0 \\
\hline
\end{tabular}

R1 = IF G01 AND G02 AND G03 AND G04AND G05 THEN P001

G01 (FALSE=0)

Maka : $\mathrm{M}_{1}\left\{\mathrm{P}_{1}\right\}=0$

$$
\mathrm{M}_{1}\{\theta\}=1-0=1
$$

G02 (FALSE $=0)$

Maka : $\mathrm{M}_{2}\left\{\mathrm{P}_{1}, \mathrm{P}_{2}\right\}=0$

$\mathrm{M}_{2}\{\theta\}=1-0=1$

Selanjutnya akan dihitung nilai densitas baru untuk kombinasi $\mathrm{M}_{3}$ seperti dibawah ini :

$$
\mathrm{M}_{2}\left\{\mathrm{P} 1, \mathrm{P}_{2}\right\}(0)
$$




\begin{tabular}{|c|c|c|}
\hline $\mathrm{M}_{1}\left\{\mathrm{P}_{1,}\right\}(0)$ & $(\mathrm{P} 1) 0$ & $\left\{\mathrm{P}_{1,}\right\} 0$ \\
\hline $\mathrm{M}_{1}\{\}(1)$ & $(\mathrm{P} 1) 0$ & $\{\Theta\} 1$ \\
\hline
\end{tabular}

Selanjutnya dihitung nilai densitas $\mathrm{M}_{3}$ sebagai berikut :

G03 (TRUE=0.24)

$$
\begin{gathered}
M^{3}\left\{P^{1}\right\}=\frac{0+0+0}{1-0}=0 \\
M_{3}\{\theta\}=\frac{1}{1-0}=1
\end{gathered}
$$

Maka : $\mathrm{M}_{4}\left\{\mathrm{P}_{1}\right\}=0,24$

$\mathrm{M}_{4}\{\theta\}=1-0,24=0,76$

\begin{tabular}{|c|c|c|}
\hline & $\mathrm{M}_{4}\left\{\mathrm{P}_{1}\right\} 0,24$ & $\mathrm{M}_{4}\{\theta\} 0,76$ \\
\hline $\mathrm{M}_{3}\left\{\mathrm{P}_{1}\right\} 0$ & 0 & 0 \\
\hline $\mathrm{M}_{3}\{\theta\} 1$ & 0,24 & 0,76 \\
\hline
\end{tabular}

-G04 $($ TRUE $=0,15)$

$$
\begin{gathered}
M_{5}\left\{P_{1}\right\}=\frac{0+0+0,24}{1-0}=0.24 \\
M_{5}\{\theta\}=\frac{0,76}{1-0}=0,76
\end{gathered}
$$

Maka : $\mathrm{M}_{6}\left\{\mathrm{P}_{1}\right\}=0,15$

$M_{6}\{\theta\}=1-0,15=0,85$

\begin{tabular}{|l|c|c|}
\hline & $\mathrm{M}_{6}\left\{\mathrm{P}_{1}\right\} 0,15$ & $\mathrm{M}_{6}\{\theta\} 0,85$ \\
\hline $\mathrm{M}_{5}\left\{\mathrm{P}_{1}\right\} 0,24$ & 0,036 & 0,204 \\
\hline $\mathrm{M}_{5}\{\theta\} 0,76$ & 0,114 & 0,646 \\
\hline
\end{tabular}

$$
\begin{gathered}
\mathrm{M}_{7}\left\{\mathrm{P}^{1}\right\}=\frac{0,036+0,204+0,114}{1-0}=0,354 \\
M_{7}\{\theta\}=\frac{0,645}{1-0}=0,646
\end{gathered}
$$

-G05 (TRUE =0,14)

Maka : $\mathrm{M}_{8}\left\{\mathrm{P}_{1}\right\}=0,14$

$\mathrm{M}_{8}\{\theta\}=1-0,14=0,86$

\begin{tabular}{|c|c|c|}
\hline & $\mathrm{M}_{8}\left\{\mathrm{P}_{1}\right\} 0,14$ & $\mathrm{M}_{8}\{\theta\} 0,86$ \\
\hline $\mathrm{M}_{7}\left\{\mathrm{P}_{1}\right\} 0,354$ & 0,04956 & 0,30444 \\
\hline $\mathrm{M}_{7}\{\theta\} 0,646$ & 0,09044 & 0,55556 \\
\hline
\end{tabular}

$$
\begin{gathered}
\mathrm{M} 9\left\{\mathrm{P}^{1}\right\}=\frac{0,04956+0,30444+0,09044}{1-0}=0,44444 \\
M 9\{\theta\}=\frac{0,55556}{1-0}=0,55556
\end{gathered}
$$

Dari perhitungan di atas, maka nilai densitas resiko terkena Kelainan Sistem Pencernaan Pada Anakjenis Gumoh yaitu sebesar 0,44444 atau $44,444 \%$.

\section{R2 = IF G04 AND G06 AND G07 AND G08 AND G09 THEN P002 \\ G04 (TRUE=0,15)}

Maka : $\mathrm{M}_{1}\left\{\mathrm{P}_{1}\right\}=0,15$

G06(FALSE=0)

$$
\mathrm{M}_{1}\{\theta\}=1-0,15=0,85
$$

Maka : $\mathrm{M}_{2}\left\{\mathrm{P}_{1}, \mathrm{P}_{2}\right\}=0$

$\mathrm{M}_{2}\{\theta\}=1-0=1$

Selanjutnya akan dihitung nilai densitas baru untuk kombinasi $\mathrm{M}_{3}$ seperti dibawah ini :

\begin{tabular}{|c|c|c|}
\hline & $\mathrm{M}_{2}\left\{\mathrm{P} 1, \mathrm{P}_{2}\right\}(0)$ & $\mathrm{M}_{2}\{\Theta\}(1)$ \\
\hline $\mathrm{M}_{1}\left\{\mathrm{P}_{1,}\right\}(0,15)$ & $(\mathrm{P} 1) 0$ & $\left\{\mathrm{P}_{1,}\right\} 0,15$ \\
\hline $\mathrm{M}_{1}\{\Theta\}(0,85)$ & $(\mathrm{P} 1) 0$ & $\{\Theta\} 0,85$ \\
\hline
\end{tabular}

Selanjutnya dihitung nilai densitas $\mathrm{M}_{3}$ sebagai berikut :

$$
\begin{gathered}
M^{3}\left\{P^{1}\right\}=\frac{0+0,15+0}{1-0}=0,15 \\
M_{3}\{\theta\}=\frac{0,85}{1-0}=0,85
\end{gathered}
$$

G07 (FALSE=0)

Maka : $\mathrm{M}_{4}\left\{\mathrm{P}_{1}\right\}=0$

$\mathrm{M}_{4}\{\theta\}=1-0=1$ 


\begin{tabular}{|c|c|c|}
\hline & $\mathrm{M}_{4}\left\{\mathrm{P}_{1}\right\} 0$ & $\mathrm{M}_{4}\{\theta\} 1$ \\
\hline $\mathrm{M}_{3}\left\{\mathrm{P}_{1}\right\} 0,15$ & 0 & 0,15 \\
\hline $\mathrm{M}_{3}\{\theta\} 0,85$ & 0 & 0,85 \\
\hline
\end{tabular}

-G08 (FALSE $=0)$

$$
\begin{gathered}
M_{5}\left\{P_{1}\right\}=\frac{0+0+0,15}{1-0}=0.15 \\
M_{5}\{\theta\}=\frac{0,85}{1-0}=0,85
\end{gathered}
$$

Maka : $\mathrm{M}_{6}\left\{\mathrm{P}_{1}\right\}=0$

$$
\mathrm{M}_{6}\{\theta\}=1-0=1
$$

\begin{tabular}{|l|r|r|}
\hline & $\mathrm{M}_{6}\left\{\mathrm{P}_{1}\right\} 0$ & $\mathrm{M}_{6}\{\theta\} 0$ \\
\hline $\mathrm{M}_{5}\left\{\mathrm{P}_{1}\right\} 0,15$ & 0 & 0,15 \\
\hline $\mathrm{M}_{5}\{\theta\} 0,85$ & 0 & 0,85 \\
\hline
\end{tabular}

-G09 (FALSE $=0)$

$$
\begin{gathered}
\mathrm{M}_{7}\left\{\mathrm{P}^{1}\right\}=\frac{0+0,15+0}{1-0}=0,15 \\
M_{7}\{\theta\}=\frac{0,85}{1-0}=0,85
\end{gathered}
$$

Maka : $\mathrm{M}_{8}\left\{\mathrm{P}_{1}\right\}=0$

$M_{8}\{\theta\}=1-0=1$

\begin{tabular}{|c|c|c|}
\hline & $\mathrm{M}_{8}\left\{\mathrm{P}_{1}\right\} 0$ & $\mathrm{M}_{8}\{\theta\} 0$ \\
\hline $\mathrm{M}_{7}\left\{\mathrm{P}_{1}\right\} 0,15$ & 0 & 0,15 \\
\hline $\mathrm{M}_{7}\{\theta\} 0,85$ & 0 & 0,85 \\
\hline
\end{tabular}

$$
\begin{gathered}
\mathrm{M} 9\left\{\mathrm{P}^{1}\right\}=\frac{0+0,15+0}{1-0}=0,15 \\
M 9\{\theta\}=\frac{0,85}{1-0}=0,85
\end{gathered}
$$

Dari perhitungan di atas, maka nilai densitas resiko terkena Kelainan Sistem Pencernaan Pada Anak jenis Disfagiayaitu sebesar 0,15 atau $15 \%$.

\section{R3 = IF G05 AND G10 AND G11 AND G12 AND G13 THEN P003}

\section{G05 (TRUE=0,14)}

Maka : $\mathrm{M}_{1}\left\{\mathrm{P}_{1}\right\}=0,14$

G10 (FALSE $=10)$

$$
\mathrm{M}_{1}\{\theta\}=1-0,14=0,86
$$

Maka : $\mathrm{M}_{2}\left\{\mathrm{P}_{1}, \mathrm{P}_{2}\right\}=0$

\begin{tabular}{|c|c|c|}
\hline & $\mathrm{M}_{4}\left\{\mathrm{P}_{1}\right\} 0$ & $\mathrm{M}_{4}\{\theta\} 1$ \\
\hline $\mathrm{M}_{3}\left\{\mathrm{P}_{1}\right\} 0,15$ & 0 & 0,14 \\
\hline $\mathrm{M}_{3}\{\theta\} 0,85$ & 0 & 0,86 \\
\hline
\end{tabular}

$$
\mathrm{M}_{2}\{\theta\}=1-0=1
$$

Selanjutnya akan dihitung nilai densitas baru untuk kombinasi $\mathrm{M}_{3}$ seperti dibawah ini :

\begin{tabular}{|c|c|c|}
\hline & $\mathrm{M}_{2}\left\{\mathrm{P} 1, \mathrm{P}_{2}\right\}(0)$ & $\mathrm{M}_{2}\{\Theta\}(1)$ \\
\hline $\mathrm{M}_{1}\left\{\mathrm{P}_{1,}\right\}(0,14)$ & $(\mathrm{P} 1) 0$ & $\left\{\mathrm{P}_{1,}\right\} 0,14$ \\
\hline $\mathrm{M}_{1}\{\Theta\}(0,86)$ & $(\mathrm{P} 1) 0$ & $\{\Theta\} 0,86$ \\
\hline
\end{tabular}

Selanjutnya dihitung nilai densitas $\mathrm{M}_{3}$ sebagai berikut :

\section{G011 (FALSE=0)}

$$
\begin{gathered}
M^{3}\left\{P^{1}\right\}=\frac{0+0,14+0}{1-0}=0,14 \\
M_{3}\{\theta\}=\frac{0,86}{1-0}=0,86
\end{gathered}
$$

Maka : $\mathrm{M}_{4}\left\{\mathrm{P}_{1}\right\}=0$

-G12 (FALSE $=0)$

$$
\begin{gathered}
M_{5}\left\{P_{1}\right\}=\frac{0+0+0,14}{1-0}=0.14 \\
M_{5}\{\theta\}=\frac{0,86}{1-0}=0,86
\end{gathered}
$$

Maka : $\mathrm{M}_{6}\left\{\mathrm{P}_{1}\right\}=0$ 


\begin{tabular}{|l|r|r|}
\hline \multicolumn{2}{|c|}{$\mathrm{M}_{6}\{\theta\}=1-0=1$} & $\mathrm{M}_{6}\{\theta\} 0$ \\
\hline $\mathrm{M}_{5}\left\{\mathrm{P}_{1}\right\} 0,14$ & $\mathrm{M}_{6}\left\{\mathrm{P}_{1}\right\} 0$ & 0,14 \\
\hline $\mathrm{M}_{5}\{\theta\} 0,86$ & 0 & 0,86 \\
\hline
\end{tabular}

-G13 (FALSE $=0)$

$$
\begin{gathered}
\mathrm{M}_{7}\left\{\mathrm{P}^{1}\right\}=\frac{0+0,14+0}{1-0}=0,14 \\
M_{7}\{\theta\}=\frac{0,86}{1-0}=0,86
\end{gathered}
$$

Maka : $\mathrm{M}_{8}\left\{\mathrm{P}_{1}\right\}=0$

$\mathrm{M}_{8}\{\theta\}=1-0=1$

\begin{tabular}{|c|c|c|}
\hline & $\mathrm{M}_{8}\left\{\mathrm{P}_{1}\right\} 0$ & $\mathrm{M}_{8}\{\theta\} 0$ \\
\hline $\mathrm{M}_{7}\left\{\mathrm{P}_{1}\right\} 0,15$ & 0 & 0,15 \\
\hline $\mathrm{M}_{7}\{\theta\} 0,85$ & 0 & 0,85 \\
\hline
\end{tabular}

$$
\begin{gathered}
\mathrm{M} 9\left\{\mathrm{P}^{1}\right\}=\frac{0+0,15+0}{1-0}=0,15 \\
M 9\{\theta\}=\frac{0,85}{1-0}=0,85
\end{gathered}
$$

Dari perhitungan di atas, maka nilai densitas resiko terkena Kelainan Sistem Pencernaan Pada Anak jenis Cyclic vomiting syndromeyaitu sebesar 0,15 atau $15 \%$.

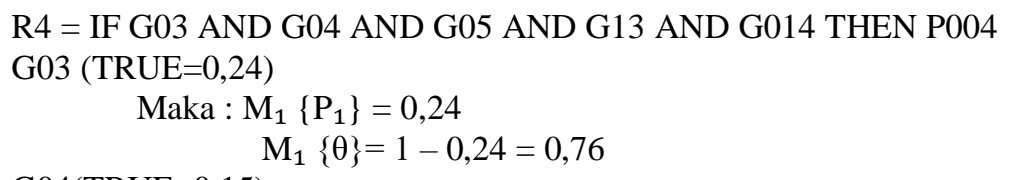

$$
\mathrm{M}_{1}\{\theta\}=1-0,24=0,76
$$

G04(TRUE=0,15)

Maka : $\mathrm{M}_{2}\left\{\mathrm{P}_{1}, \mathrm{P}_{2}\right\}=0,15$

$\mathrm{M}_{2}\{\theta\}=1-0,15=0,85$

Selanjutnya akan dihitung nilai densitas baru untuk kombinasi $\mathrm{M}_{3}$ seperti dibawah ini :

\begin{tabular}{|c|c|c|}
\hline & $\mathrm{M}_{2}\left\{\mathrm{P} 1, \mathrm{P}_{2}\right\}(0,15)$ & $\mathrm{M}_{2}\{\Theta\}(0,85)$ \\
\hline $\mathrm{M}_{1}\left\{\mathrm{P}_{1,}\right\}(0,24)$ & $(\mathrm{P} 1) 0,036$ & $\left\{\mathrm{P}_{1,}\right\} 0,204$ \\
\hline $\mathrm{M}_{1}\{\Theta\}(0,76)$ & $(\mathrm{P} 1) 0,114$ & $\{\Theta\} 0,646$ \\
\hline
\end{tabular}

Selanjutnya dihitung nilai densitas $\mathrm{M}_{3}$ sebagai berikut :

G05 (TRUE=0,14)

$$
\begin{gathered}
M^{3}\left\{P^{1}\right\}=\frac{0,036+0,204+0,114}{1-0}=0,354 \\
M_{3}\{\theta\}=\frac{0,646}{1-0}=0,646
\end{gathered}
$$

Maka : $\mathrm{M}_{4}\left\{\mathrm{P}_{1}\right\}=0,14$

$\mathrm{M}_{4}\{\theta\}=1-0,14=0,86$

\begin{tabular}{|c|c|c|}
\hline & $\mathrm{M}_{4}\left\{\mathrm{P}_{1}\right\} 0,14$ & $\mathrm{M}_{4}\{\theta\} 0,86$ \\
\hline $\mathrm{M}_{3}\left\{\mathrm{P}_{1}\right\} 0,354$ & 0,04956 & 0,30444 \\
\hline $\mathrm{M}_{3}\{\theta\} 0,646$ & 0,09044 & 0,55556 \\
\hline
\end{tabular}

-G13 (TRUE=0,23)

$$
\begin{aligned}
& M_{5}\left\{P_{1}\right\}=\frac{0,04956+0,30444+0,09044}{1-0}=0,44444 \\
& M_{5}\{\theta\}=\frac{0,55556}{1-0}=0,55556
\end{aligned}
$$

Maka : $\mathrm{M}_{6}\left\{\mathrm{P}_{1}\right\}=0,23$

$\mathrm{M}_{6}\{\theta\}=1-0,23=0,77$

$-\mathrm{G} 14(\mathrm{FALSE}=0)$

\begin{tabular}{|l|c|c|}
\hline & $\mathrm{M}_{6}\left\{\mathrm{P}_{1}\right\} 0,23$ & $\mathrm{M}_{6}\{\theta\} 0,77$ \\
\hline $\mathrm{M}_{5}\left\{\mathrm{P}_{1}\right\} 0,44444$ & 0,1022212 & 0,3422188 \\
\hline $\mathrm{M}_{5}\{\theta\} 0,55556$ & 0,1277788 & 0,4277812 \\
\hline
\end{tabular}

$$
\begin{gathered}
\mathrm{M}_{7}\left\{\mathrm{P}^{1}\right\}=\frac{0,1022212+0,3422188+0,1277788}{1-0}=0,5722188 \\
M_{7}\{\theta\}=\frac{0,4277812}{1-0}=0,4277812
\end{gathered}
$$


Maka : $\mathrm{M}_{8}\left\{\mathrm{P}_{1}\right\}=0$

$\mathrm{M}_{8}\{\theta\}=1-0=1$

\begin{tabular}{|c|c|c|}
\hline & $\mathrm{M}_{8}\left\{\mathrm{P}_{1}\right\} 0$ & $\mathrm{M}_{8}\{\theta\} 1$ \\
\hline $\mathrm{M}_{7}\left\{\mathrm{P}_{1}\right\} 0,5722188$ & 0 & 0,5722188 \\
\hline $\mathrm{M}_{7}\{\theta\} 0,4277812$ & 0 & 0,4277812 \\
\hline
\end{tabular}

$$
\begin{gathered}
\mathrm{M} 9\left\{\mathrm{P}^{1}\right\}=\frac{0+0,5722188+0}{1-0}=0,5722188 \\
M 9\{\theta\}=\frac{0,4277812}{1-0}=0,4277812
\end{gathered}
$$

Dari perhitungan di atas, maka nilai densitas resiko terkena Kelainan Sistem Pencernaan Pada Anak jenis Kolikyaitu sebesar 0,5722188atau 57,22188\%.

\section{R5 = IF G05 AND G12 AND G14 AND G15 AND G016 THEN P005 \\ G05 (TRUE=0,14)}

\section{G12(FALSE $=0$ )}

Maka : $\mathrm{M}_{1}\left\{\mathrm{P}_{1}\right\}=0,14$

$$
\mathrm{M}_{1}\{\theta\}=1-0,14=0,86
$$

Maka: $\mathrm{M}_{2}\left\{\mathrm{P}_{1}, \mathrm{P}_{2}\right\}=0$

$\mathrm{M}_{2}\{\theta\}=1-0=1$

Selanjutnya akan dihitung nilai densitas baru untuk kombinasi $\mathrm{M}_{3}$ seperti dibawah ini :

\begin{tabular}{|c|c|c|}
\hline & $\mathrm{M}_{2}\left\{\mathrm{P} 1, \mathrm{P}_{2}\right\}(0)$ & $\mathrm{M}_{2}\{\Theta\}(1)$ \\
\hline $\mathrm{M}_{1}\left\{\mathrm{P}_{1,}\right\}(0,14)$ & $(\mathrm{P} 1) 0$ & $\left\{\mathrm{P}_{1,}\right\} 0,14$ \\
\hline $\mathrm{M}_{1}\{\Theta\}(0,86)$ & $(\mathrm{P} 1) 0$ & $\{\Theta\} 0,86$ \\
\hline
\end{tabular}

Selanjutnya dihitung nilai densitas $\mathrm{M}_{3}$ sebagai berikut :

G14 (FALSE=0)

$$
\begin{gathered}
M^{3}\left\{P^{1}\right\}=\frac{0+0,14+0}{1-0}=0,14 \\
M_{3}\{\theta\}=\frac{0,86}{1-0}=0,86
\end{gathered}
$$

Maka : $\mathrm{M}_{4}\left\{\mathrm{P}_{1}\right\}=0$

\begin{tabular}{|c|c|c|}
\hline & $\mathrm{M}_{4}\{\theta\}=1-0=1$ & $\mathrm{M}_{4}\{\theta\} 1$ \\
\hline & $\mathrm{M}_{4}\left\{\mathrm{P}_{1}\right\} 0$ & 0,14 \\
\hline $\mathrm{M}_{3}\left\{\mathrm{P}_{1}\right\} 0,14$ & 0 & 0,86 \\
\hline
\end{tabular}

-G15 (FALSE $=0)$

$$
\begin{gathered}
M_{5}\left\{P_{1}\right\}=\frac{0+0,14+0}{1-0}=0.14 \\
M_{5}\{\theta\}=\frac{0,85}{1-0}=0,86
\end{gathered}
$$

Maka : $\mathrm{M}_{6}\left\{\mathrm{P}_{1}\right\}=0$

$$
\mathrm{M}_{6}\{\theta\}=1-0=1
$$

\begin{tabular}{|l|c|c|}
\hline & $\mathrm{M}_{6}\left\{\mathrm{P}_{1}\right\} 0$ & $\mathrm{M}_{6}\{\theta\} 0$ \\
\hline $\mathrm{M}_{5}\left\{\mathrm{P}_{1}\right\} 0,14$ & 0 & 0,14 \\
\hline $\mathrm{M}_{5}\{\theta\} 0,86$ & 0 & 0,86 \\
\hline
\end{tabular}

$-\mathrm{G} 16(\mathrm{FALSE}=0)$

$$
\begin{gathered}
\mathrm{M}_{7}\left\{\mathrm{P}^{1}\right\}=\frac{0+0,14+0}{1-0}=0,14 \\
M_{7}\{\theta\}=\frac{0,86}{1-0}=0,86
\end{gathered}
$$

Maka : $\mathrm{M}_{8}\left\{\mathrm{P}_{1}\right\}=0$

$\mathrm{M}_{8}\{\theta\}=1-0=1$

\begin{tabular}{|c|c|c|}
\hline & $\mathrm{M}_{8}\left\{\mathrm{P}_{1}\right\} 0$ & $\mathrm{M}_{8}\{\theta\} 0$ \\
\hline $\mathrm{M}_{7}\left\{\mathrm{P}_{1}\right\} 0,14$ & 0 & 0,14 \\
\hline $\mathrm{M}_{7}\{\theta\} 0,86$ & 0 & 0,86 \\
\hline
\end{tabular}

$$
\begin{gathered}
\mathrm{M} 9\left\{\mathrm{P}^{1}\right\}=\frac{0+0,14+0}{1-0}=0,14 \\
M 9\{\theta\}=\frac{0,86}{1-0}=0,86
\end{gathered}
$$


Dari perhitungan di atas, maka nilai densitas resiko terkena Kelainan Sistem Pencernaan Pada Anak jenis Diare Fungsionalyaitu sebesar 0,14 atau $14 \%$.

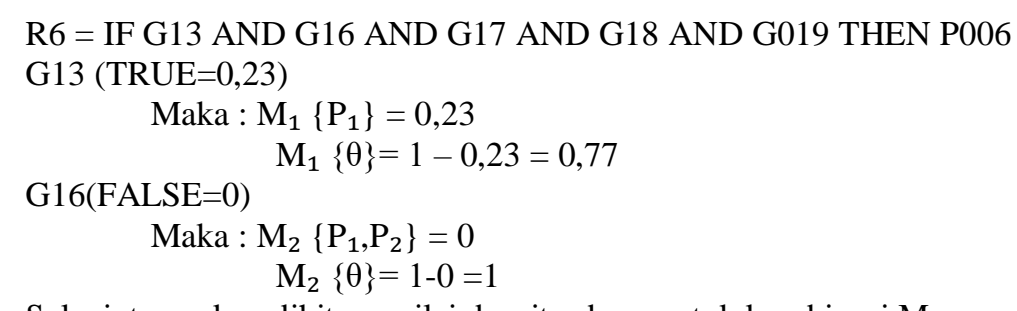

Selanjutnya akan dihitung nilai densitas baru untuk kombinasi $\mathrm{M}_{3}$ seperti dibawah ini :

\begin{tabular}{|c|c|c|}
\hline & $\mathrm{M}_{2}\left\{\mathrm{P} 1, \mathrm{P}_{2}\right\}(0)$ & $\mathrm{M}_{2}\{\Theta\}(1)$ \\
\hline $\mathrm{M}_{1}\left\{\mathrm{P}_{1,}\right\}(0,23)$ & $(\mathrm{P} 1) 0$ & $\left\{\mathrm{P}_{1,}\right\} 0,23$ \\
\hline $\mathrm{M}_{1}\{\Theta\}(0,76)$ & $(\mathrm{P} 1) 0$ & $\{\Theta\} 0,76$ \\
\hline
\end{tabular}

Selanjutnya dihitung nilai densitas $\mathrm{M}_{3}$ sebagai berikut :

G17 (FALSE=0)
\begin{tabular}{|c|c|c|} 
Maka : $\mathrm{M}_{4}\left\{\mathrm{P}_{1}\right\}=0$ \\
$\mathrm{M}_{4}\{\theta\}=1-0=1$ & $\mathrm{M}_{4}\left\{\mathrm{P}_{1}\right\} 0$ & $\mathrm{M}_{4}\{\theta\} 1$ \\
\hline & 0 & 0,23 \\
\hline $\mathrm{M}_{3}\left\{\mathrm{P}_{1}\right\} 0,23$ & 0 & 0,76 \\
\hline $\mathrm{M}_{3}\{\theta\} 0,76$ & 0 & 10,0 \\
\hline
\end{tabular}

$$
\begin{gathered}
M^{3}\left\{P^{1}\right\}=\frac{0+0,23+0}{1-0}=0,23 \\
M_{3}\{\theta\}=\frac{0,76}{1-0}=0,76
\end{gathered}
$$

$$
\begin{gathered}
M_{5}\left\{P_{1}\right\}=\frac{0+0+0,23}{1-0}=0.23 \\
M_{5}\{\theta\}=\frac{0,76}{1-0}=0,76
\end{gathered}
$$

-G18 (FALSE $=0)$

Maka : $\mathrm{M}_{6}\left\{\mathrm{P}_{1}\right\}=0$

$$
\mathrm{M}_{6}\{\theta\}=1-0=1
$$

\begin{tabular}{|l|r|r|}
\hline & $\mathrm{M}_{6}\left\{\mathrm{P}_{1}\right\} 0$ & $\mathrm{M}_{6}\{\theta\} 0$ \\
\hline $\mathrm{M}_{5}\left\{\mathrm{P}_{1}\right\} 0,23$ & 0 & 0,23 \\
\hline $\mathrm{M}_{5}\{\theta\} 0,76$ & 0 & 0,76 \\
\hline
\end{tabular}

\section{-G19 (FALSE $=0)$}

$$
\begin{gathered}
\mathrm{M}_{7}\left\{\mathrm{P}^{1}\right\}=\frac{0+0,23+0}{1-0}=0,23 \\
M_{7}\{\theta\}=\frac{0,76}{1-0}=0,76
\end{gathered}
$$

Maka : $\mathrm{M}_{8}\left\{\mathrm{P}_{1}\right\}=0$

$\mathrm{M}_{8}\{\theta\}=1-0=1$

\begin{tabular}{|c|c|c|}
\hline & $\mathrm{M}_{8}\left\{\mathrm{P}_{1}\right\} 0$ & $\mathrm{M}_{8}\{\theta\} 0$ \\
\hline $\mathrm{M}_{7}\left\{\mathrm{P}_{1}\right\} 0,23$ & 0 & 0,23 \\
\hline $\mathrm{M}_{7}\{\theta\} 0,76$ & 0 & 0,76 \\
\hline
\end{tabular}

$$
\begin{gathered}
\mathrm{M} 9\left\{\mathrm{P}^{1}\right\}=\frac{0+0,23+0}{1-0}=0,23 \\
M 9\{\theta\}=\frac{0,76}{1-0}=0,76
\end{gathered}
$$

Dari perhitungan di atas, maka nilai densitas resiko terkena Kelainan Sistem Pencernaan Pada Anak jenis Sembelityaitu sebesar 0,23 atau $23 \%$.

Selanjutnya akan dibandingkan hasil dari probabilitas dari masing-masing penyakit sebagai berikut:

1. Gumoh $=44,444 \%$

2. Disfagia $=15 \%$

3. Cyclic vomiting syndrome $=15 \%$

4. Kolik $=57,22188 \%$

5. Diare Fungsional $=14 \%$

6. Sembelit $=23 \%$

Berdasarkan nilai diatas, maka pasien dapat di diagnosa terkena penyakit Kolik dengan nilai 57,22188\%. 


\section{KESIMPULAN}

Dari penulisan penelitian ini mulai dari tahapan analisa permasalahan yang ada hingga pengujian sistem yang baru dirancang maka dapat diambil beberapa kesimpulan, yaitu :

1. Sistem pakar yang dirancang dapat mendiagnosa penyebab Kelainan pada sistem pencernaan anak karena didalam sistem pakar ini diberikan pengetahuan berupa gejala-gejala yang digunakan sebagai masukan terhadap konsultasi user dan dari gejala yang dipilih akan diolah dengan menggunakan metode Dampster Shafer sehingga menghasilkan diagnosa mengenai penyakit dan persentasenya, hasil tersebut dapat menjadi masukan pengetahuan bagi masyarakat,

2. Pada sistem pakar ini terdapat fakta-fakta atau gejala-gejala mengenai Kelainan pada sistem pencernaan anak yang digunakan sebagai pengetahuan dasar terhadap pendiagnosaan penyakit Kelainan pada sistem pencernaan anak.

3. Didalam sistem pakar ini terdapat pengobatan yang dapat mengatasi Kelainan pada sistem pencernaan anak, dimana pencegahan tersebut tergantung pada tingkat persentase diagnosa Kelainan pada sistem pencernaan anak yang dihasilkan.

\section{DAFTAR PUSTAKA}

Anisya, A. (2013). Aplikasi sistem database rumah sakit terpusat pada rumah sakit umum (rsu)'aisyiyah padang dengan menerapkan open source (php-mysql. Jurnal Momentum, 15(2).

Budiman, C. S., \& Rismawan, t. Aplikasi sistem pakar untuk mendiagnosa penyakit gangguan saraf dengan metode dempster shafer berbasis android. Jurnal Coding Sistem Komputer Universitas Tanjungpura, 4(3).

Dahria, M., Silalahi, R., \& Ramadhan, M. (2013). Sistem Pakar Metode Dampster-Shafer Untuk Menentukan Jenis Gangguan Perkembangan Pada Anak. Universitas Trihuna Darma, Medan.

Hariadi, F. (2012). Pembuatan sistem informasi perpustakaan pada SDN Sukoharjo pacitan berbasis web. IJNS-Indonesian Journal on Networking and Security, 2(4).

Indraswari, D. P., Soebroto, A. A., \& Marhaendraputro, E. A. (2015). Sistem Pendukung Keputusan Deteksi Dini Penyakit Stroke Menggunakan Metode Dempster-Shafer. Journal of Environmental Engineering and Sustainable Technology, 2(2), 97-104.

Istiqomah, Y. N., \& Fadlil, A. (2013). Sistem Pakar Untuk Mendiagnosa Penyakit Saluran Pencernaan Menggunakan Metode Dempster Shafer. JSTIE (Jurnal Sarjana Teknik Informatika)(E-Journal), 1(1), 32-41.

Kurmasela, G. A. P., \& Sevani, G. N. (2015). Aplikasi Diagnosa Gizi Buruk Pada Balita Menggunakan Metode Pembobotan (Studi Kasus: Kecamatan Nusaniwe, Kota Ambon). ComTech: Computer, Mathematics and Engineering Applications, 6(1), 20-30.

Limantara, A. D., Winarto, S. W., \& Mudjanarko, S. W. (2017). Sistem pakar pemilihan model perbaikan perkerasan lenturberdasarkan indeks kondisi perkerasan (PCI). Prosiding Semnastek.

Mandala, Eka Praja Wiyata. 2015. Web Programming Project 1 “e.p.w.m Forum”. Yogyakarta: ANDI

Nugroho, D., \& Kustanto, K. (2013). Sistem pakar untuk diagnosis penyakit ginjal dengan metode forward chaining. Jurnal Teknologi Informasi dan Komunikasi (TIKomSiN), 1(2).

Octavina, Y., \& Fadlil, A. (2014). Sistem Pakar Untuk Mendiagnosa Penyakit Pada Saluran Pernafasan Dan Paru Menggunakan Metode Certainty Factor. JSTIE (Jurnal Sarjana Teknik Informatika)(E-Journal), 2(2), 326-335.

Penelitian, K. (2013). Aplikasi diagnosa gejala demam pada balita menggunakan metode certainty factor (cf) dan jaringan syaraf tiruan (jst).

Prasetio, Adhi. 2014. Buku Sakti Webmaster (PHP \& MySQL, HTML \& CSS, HTMLS \& CSS3, JavaScripi). Jakarta Selatan : Mediakita

Puspitasari, T., Susilo, B., \& Coastera, F. F. (2016). Implementasi Metode Dempster-Shafer Dalam Sistem Pakar Diagnosa Anak Tunagrahita Berbasis Web. Rekursif: Jurnal Informatika, 4(1).

Qamaruzzaman, M. H. (2016). Sistem Pakar Untuk Mendiagnosa Penyakit Mata Pada Manusia Menggunakan Teorema Bayes. IJNS-Indonesian Journal on Networking and Security, 5(4).

Rifati, I. S. M. (2016, December). Pengembangan sistem pakar mendeteksi penyakit pencernaan menggunakan metode naive bayes berbasis web. In Seminar Nasional Ilmu Pengetahuan dan Teknologi Komputer (pp. 394-INF).

Sagita Rinandi Awan, Hari Sugiarto. 2016. Penerapan Metode Waterfall PadaSistem Informasi Penjualan Furniture Berbasis Web. Indonesian Journal on Networking and Security. Vol.5, No.4. ISSN: 2302-5700

Sardiarinto, dkk. 2015. Rancang Bangun Sistem Reservasi Hotel Menggunakan Metode Waterfall. Jurnal Bianglala Informatika. Vol.3, No.1. ISSN: 2338-9761

Situmorang, A. H., Hakim, I. N., \& Shofyan, M. (2016). Aplikasi Sistem Pakar Untuk Mendiagnosa Penyakit Pencernaan Pada Manusia Menggunakan Metode Forward Channing. Semnasteknomedia Online, 4(1), 3-6.

Simajuntak, P. (2016). Analisis model view controller (mvc) pada bahasa php. Journal Information System Development (ISD), 1(2).

Surmayanti. 2016. Sistem informasi promosi obyek wisata Pulau pamutusan. Jurnal KomTekInfo. Vol.3, No.1. ISSN: 25028758

Sharma, H., \& Patel, N. (2014). Effectiveness of tens versus intermittent cervical traction in patients with cervical radiculopathy. International Journal of Physiotherapy and Research, 2, 787-92. 
S, Rosa A., M. Shalahuddin. 2014. Rekayasa Perangkat Lunak Terstruktur dan Informatika

Berorientasi Objek, Bandung :

Swara, Ganda Yoga, Yunes Pebriadi. 2016. Rekayasa Perangkat Lunak Pemesanan Tiket Bioskop Berbasis Web. Jurnal TEKNOIF. Vol.4, No.2. ISSN: 2338-2724

Waryanta, I. W. R., Putra, I. K. G. D., \& Purnawan, I. K. A. Deteksi Sepsis pada Bayi Menggunakan Metode DempsterShafer. Lontar Komputer: Jurnal Ilmiah Teknologi Informasi, 13-21

Yuhendra, Riza Eko Yulianto. 2015. Rekayasa perangkat lunak pengolahan data distribusi obatobatan di pt. Anugrah pharmindo lestari berbasis web, Padang

Zakaria, K. (2015). Sistem Pakar Diagnosa Penyakit Gigi Dan Mulut Menggunakan Metode Dempster Shafer. In Seminar Informatika Aplikatif Polinema. 